\title{
Development of suitable formula for ready-to-drink healthy mixture of chicory and coffee
}

\author{
Narin Charoenphun ${ }^{1}$ iD, Ratchanee Puttha ${ }^{2}$ iD
}

\author{
${ }^{1}$ Burapha University Sakaeo Campus, Faculty of Agricultural Technology, Watthananakhon, Sakaeo, Thailand \\ ${ }^{2}$ Maejo University, Faculty of Agricultural Production, San Sai, Chiang Mai, Thailand \\ Contact authors: narinch@go.buu.ac.th, ratchanee_pt@mju.ac.th \\ Received in July 14, 2020 and approved in January 22, 2021
}

\section{ABSTRACT}

Chicory root coffee currently gains popularity as a coffee substitute because of its health benefits. The purpose of this research is to develop ready-todrink healthy mixture of chicory and coffee (RDHCC) products. Fifteen trained panelists were invited to evaluate the aroma intensity 6 ratios of chicory and coffee mixture by sensory rating scales on a straight line at the distance of $150 \mathrm{~mm}$. The ratio of 2:3 of chicory and coffee had the highest rating. The ratio was further used for development of RDHCC recipes consisting of chicory-coffee mixture, coffee creamer and sugar. Nine recipes were evaluated by 9-point hedonic scale with twenty trained panelists, and the best recipe was obtained from the ingredients of $15 \%$ chicory-coffee mixture, $32.5 \%$ coffee creamer and $52.5 \%$ sugar. Other ingredients were investigated to replace coffee creamer, and soybean milk powder had the highest overall liking score $(7.45 \pm 0.94)$ and it was not significant different from $8.15 \pm 1.09$ of coffee creamer. Other sweeteners were included in the recipe to replace sugar, and stevia extract had the highest overall liking score $(7.30 \pm 1.00)$, which was not different from $7.45 \pm 0.94$ of sugar. Herbs were finally incorporated into the RDHCC recipe, and cordyceps (Cordyceps militaris) had the highest overall liking score ( $7.15 \pm 1.04)$, which was not different from that of the original recipe without herb. The RDHCC products developed by the project are promising for commercialization to serve the demand for coffee with low calorie, low caffeine intake and health benefits.

Key words: Health benefits; Inulin; Jerusalem artichoke; Soy milk; Stevia.

\section{INTRODUCTION}

Coffee is consumed in all parts of the world. According to International Coffee Organization - ICO (2020), world coffee production is estimated at 169.34 million bags in $2019 / 20$, while global consumption is estimated to rise by $0.3 \%$ to 168.39 million bags in $2019 / 20$. Although the world consumption is increased, the surplus is estimated at 952,000 bags. Brazil is the world's largest coffee producer, followed by Vietnam and Colombia, while the European Union countries are the largest consumers, followed by the United States and Brazil. There are 2 popularly varieties of coffee. The most popularly is Arabica (Coffea Arabica) and the second is Robusta (Coffea canephora).

In general, coffee beans contain caffeine, which stimulates the central nervous system of the brain. The coffee bean containing 100-200 mg of caffeine has the effect of making the body alert, refreshed, rejuvenated, and diuretic. If the amount of caffeine up to $250-500 \mathrm{mg}$, it stimulates the heart and may cause seizures. Caffeine is a fast-acting substance that is absorbed into the bloodstream in just $5 \mathrm{~min}$ and enters the brain within $20-30 \mathrm{~min}$. Safe caffeine intake is $100-300 \mathrm{mg}$ per day. In addition, coffee beans also have a variety of vitamins such as thiamine, riboflavin, niacin, choline, and ascorbic acid.

Consumption of coffee containing high amounts of sugar, milk, or coffee creamer may cause chronic diseases such as high blood pressure, diabetes, heart disease, fat embolism syndrome, obesity, and other non-contagious diseases. There are also recommendations for drinking coffee. For example, the pregnant women should not drink coffee because caffeine will affect the fetus Including after birth because caffeine may enter the baby through breast milk. Children under 10 years old should not drink coffee because caffeine will stop the growth hormone that causing the body does not grow (Sengpiel et al., 2013). Therefore, the development of mixture of chicory and coffee is an interesting option for groups with restrictions on consumption and those who are health conscious.

Chicory (Cichorium intybus L.) is a member of Asteracea family, and it is a close relative of sunflower (Helianthus annuus L.) and Jerusalem artichoke (Helianthus tuberosus L.). While sunflower and Jerusalem artichoke were domesticated in America, chicory was domesticated in Europe, and it has been distributed and cultivated in many countries (Moon et al., 2019).

Chicory is an inulin containing crop like Jerusalem artichoke and globe artichoke (Cynara cardunculus). Inulin is a polysaccharide with health benefits. Inulin is not digested into short chains of sugar in digastrics system. Therefore, inulin functions as a soluble food fiber that is useful for excretion system. Consuming a gram of inulin provides just 1.4 calories. It helps control blood sugar and fat levels and has a low Glycemic index. In addition, inulin has a prebiotic property, which is the food of human microbes especially the microbes that are beneficial to the body and increase immunity to the body (Tanjor et al., 2012). 
While Jerusalem artichoke and globe artichoke are used for food supplement, animal feed, and tea, chicory root is used as a coffee substitute because of its bitter taste. Chicory is harvest at the age of about 120 days. Roots are cleaned after harvest, peeled, cut into small pieces, dried and blended into fine powder in a blender. Chicory root powder is used for flavoring or brewed instead of coffee (Indzere et al., 2018).

Chicory is added as a substitute for some part of coffee to reduce caffeine and enhance inulin in coffee. Adding chicory in coffee for new products may increase coffee consumption and reduce the surplus of coffee production because new products may generate new market segment. Coffee is usually consumed with sugar and creamer. However, most creamer brands available in the market are non-dairy and contain other types of fat other than butter, or cream with butter fat mixed not less than $30 \%$ of total fat (Do et al., 2019). Regular consumption of sugar and creamer may affect the health of diabetic patients, heart disease, high blood pressure, a fat embolism syndrome, obesity or people with dietary restrictions that are high in sugar and fat.

The objective of this research is to study the suitable formula to produce ready-to-drink healthy mixture of chicory and coffee (RDHCC). The other raw materials were used for replacing the coffee creamer and sugar. In addition, local herbs were added to improve the quality of RDHCC products. Physicochemical properties and sensory acceptability of consumers were evaluated for selection of the prototype formula. It is an alternative for consumers with dietary restrictions and healthy consumers.

\section{MATERIAL AND METHODS}

The development of RDHCC products was divided into five steps including evaluation of coffee and chicory ratios, evaluation of the ratios among coffee-chicory mixture, coffee creamer and refined sugar, evaluation of creamer substitutes, evaluation of sweetener substitutes, and evaluation of herb additives.

\subsection{Chicory and coffee ratios}

Raw coffee bean was purchased from Doi Angkang, Chiang Mai, Thailand, and roasted chicory root was purchased from Worldwide Botanicals, Santa Barbara, CA. Six ratios of chicory and coffee including $0: 5,1: 4,2: 3,3: 2,4: 1$ and 5: 0 were evaluated in this study. Chicory root and coffee beans were crushed with a grinder (Dxfill, Model DXM-500, China) at a speed of level 2 for $2 \mathrm{~min}$. The power samples of chicory and coffee were mixed according to the above ratios. The sample of 20 grams for each ratio was extracted through coffee filter paper.
The sample of 20 grams was added in the coffee filter paper and brewed by pouring hot water through the sample on the filter paper. Each sample was replicated three times. The various flavoring substances were extracted from coffee and chicory. The $200 \mathrm{~mL}$ of hot water at temperature of $95^{\circ} \mathrm{C}$ was used for extraction of each sample for $3 \mathrm{~min}$.

The total soluble solid was measured by digital refractometer (HANNA Instruments, Romania). pH was measured by $\mathrm{pH}$ meter (PH Meter 0.01 , China). The color values were measured by colorimeter (WR10QC, China). The CIE system was evaluated by $\mathrm{L}^{*}$ or brightness $(0=$ black, 100 $=$ white $), a^{*}(+a=$ red, $-\mathrm{a}=$ green $)$ and $b^{*}(+b=$ yellow, $-b$ $=$ Blue). Inulin content was analyzed by spectrophotometric method with minor modification (Puttha et al., 2012).

Six ratios of the mixture were evaluated for sensory parameters by 15 trained panelists using ASTM method (Stone, 1992). The important intensity of color, coffee aroma, sweetness, bitterness and overall liking were expressed by generic descriptive analysis. Intensity score was investigated on a straight line $150 \mathrm{~mm}$. This work has been already considered the ethics in research with human for sensory analysis (HS005/2563). The quality parameters of the mixture consisted of total soluble solid, $\mathrm{pH}$, color value, inulin content, and sensory evaluation score were determined for selecting the appropriate ratio of chicory and coffee. The ratio with the best scores was used in the next steps.

\subsection{Chicory-coffee mixture, coffee creamer and white (refined) sugar ratios}

The ratio of 2:3 of chicory and coffee was selected for further studies (sub-headings 2.2 to 2.5). The ratios among chicory-coffee mixture, creamer and refined sugar were studied by using mixture designs. Coffee creamer was purchased from Nestle (Thai) Ltd., Samut Prakan, Thailand, and refined sugar was purchased from Mitrphol, Suphan Buri, Thailand. The independent factors were proportions of different components of chicory-coffee mixture $(10-20 \%)$, coffee creamer (20$40 \%$ ) and refined sugar (40-60\%), respectively. The points on designated trapezoid area were selected for the study. The nine formulae of RDHCC products from mixture design were investigated (Table 1). Chicory-coffee mixture (ratio 2:3) was extracted by the method described previously in sub-heading 2.1. For each formula, the creamer and refined sugar were added in the extracted chicory-coffee mixture, and the final mixture was stirred until the ingredients were mixed well. Data were recorded for total soluble solids, $\mathrm{pH}$, and color values. Sensory parameters were evaluated by 20 trained panelists. The parameters for liking of appearance, color, coffee aroma, taste and overall liking were expressed by 9-point hedonic scale. The appropriate formula was selected for developing to RDHCC products. 
Table 1: Formula of coffee by mixture design.

\begin{tabular}{cccccccccc}
\hline \multirow{2}{*}{ Ingredient } & \multicolumn{10}{c}{ Formula } \\
\cline { 2 - 9 } & 1 & 2 & 3 & 4 & 5 & 6 & 7 & 8 \\
\hline Mixed coffee with chicory (\%) & 17.4 & 12.4 & 20.0 & 10.0 & 17.4 & 12.4 & 20.0 & 15.0 & 10.0 \\
Coffee creamer (\%) & 26.3 & 36.3 & 20.0 & 30.0 & 36.3 & 31.3 & 40.0 & 32.5 & 40.0 \\
Sugar (\%) & 56.3 & 51.3 & 60.0 & 60.0 & 46.3 & 56.3 & 40.0 & 52.5 & 50.0 \\
\hline
\end{tabular}

\subsection{Creamer substitutes}

The formula containing 15\% chicory-coffee mixture, $32.5 \%$ coffee creamer, and $52.5 \%$ sugar was selected for evaluation of creamer substitutes. The creamer substitutes including Jerusalem artichoke powder, soybean milk powder, germinated riceberry powder (germ only), and golden banana powder were used for replacement $100 \%$ of coffee creamer. Riceberry is a new type of non-glutinous rice with high anthocyanins developed for special market. Jerusalem artichoke powder was purchased from Saonfarm, Nakhon Ratchasima, Thailand, soybean milk powder was purchased from Nutrimate, Pathum Thani, Thailand, germinated riceberry powder was purchased from VVIP, Bangkok, Thailand, and golden banana powder was purchased from Organic, Bangkok, Thailand. Five recipes including four creamer substitutes and control were evaluated.

The method for coffee preparation was described previously in sub heading 2.1. The total soluble solids, $\mathrm{pH}$, and color values were measured. Sensory parameters were evaluated by 20 trained panelists. The parameters for liking of appearance, color, coffee aroma, taste, and overall liking were expressed by 9-point hedonic scale. The appropriate raw materials for replacement of coffee creamer were selected to study in the next steps.

\subsection{White sugar substitutes}

The formula containing $15 \%$ chicory-coffee mixture, $32.5 \%$ coffee creamer, and $52.5 \%$ sugar was selected for evaluation of creamer substitutes. Soybean milk powder (in subheading 2.3) was selected as a creamer substitute. Therefore, Chicory-coffee mixture at the ratio of 2:3 and soybean milk powder were used in the study of white sugar substitutes. Stevia (Stevia rebaudiana) extract and erythritol coffee were used as sweeteners for placing $100 \%$ white sugar in the formula. They were added at the rate of $0.5 \%$ in solution of chicory-coffee mixture. Stevia extract and erythritol were purchased from Krungthepchemi CO., LTD, Bangkok, Thailand. Three recipes including two sweeteners and control were evaluated.

Chicory-coffee mixture was prepared according to the method described in sub-heading 2.1. Sensory parameters were evaluated by 20 trained panelists. The parameters for of liking of appearance, color, coffee aroma, taste, and overall liking were expressed by 9 -point hedonic scale. The appropriate sugar substitute for replacement of white sugar was selected to study in the next step.

\subsection{Herbal supplements}

The last step of the development of the most appropriate formula for RDHCC products was to herb select using the most appropriate formula from the above studies. The most appropriate formula included chicory-coffee mixture at the ratio of 2:3, soybean milk powder, and stevia extract.

The $0.1 \%$ of cordyceps (Cordyceps sinensis), ginger (Zingiber officinalis) root powder, lemongrass (Cymbopogon citratus), and fingerroot (Boesenbergia rotunda L.) powder were added in RDHCC products. Cordyceps was purchased from Phaya Cordy, Bangkok, Thailand. Ginger root powder, lemongrass, and fingerroot powder were purchased from Herb powder, Bangkok, Thailand. Chicory-coffee mixture was prepared by the method described in sub-heading 2.1. Therefore, five recipes (four herbs and control) were evaluated at the final step.

Twenty trained panelists were invited to evaluated sensory parameters of the products. The parameters for liking of appearance, color, coffee aroma and taste, and overall liking were expressed by 9 -point hedonic scale.

\subsection{Statistical analysis}

The statistical technique one-way ANOVA was used to compare the means of each group. Duncan's new multiplerange Test (DMRT) was used to compare the differences in average values at the $95 \%$ confidence level (Duncan, 1955).

Additional analysis was performed for sub-heading 2.2. The regression analysis was performed by the statistical program using the following equation;

$y=\beta_{1} x_{1}+\beta_{2} x_{2}+\beta_{3} x_{3}+\beta_{4} x_{1} x_{2}+\beta_{5} x_{1} x_{3}+\beta_{6} x_{2} x_{3}$,

where $y$ is the quality value; $\beta$ is the coefficient of each variable in the equation; $\mathrm{x}_{1}$ is the amount of mixed coffee with chicory; $\mathrm{x}_{2}$ is the amount of coffee creamer; $\mathrm{x}_{3}$ is the amount of sugar. The contour plot was overlapped to find the right ratio for the amounts of chicory-coffee mixture, coffee creamer and sugar. The quality parameters of RDHCC products consisted of total soluble solid, $\mathrm{pH}$, color values, and sensory parameters were determined for selecting the appropriate formula of RDHCC products. 


\section{RESULTS}

\subsection{Coffee and chicory ratios}

Chicory-coffee ratios were significantly different $(\mathrm{P}$ $\leq 0.05$ ) for total soluble solid, inulin content, $\mathrm{pH}$, and color values including $\mathrm{L}^{*}, \mathrm{a}^{*}$ and $\mathrm{b}^{*}$ (Table 2 ). Total soluble solids ranged between 3.40 and $13.57^{\circ} \mathrm{Brix}$, and inulin contents ranged between 0.01 and $9.59 \mathrm{~g} .100 \mathrm{~g}^{-1}$ dry weight, whereas $\mathrm{pH}$ values ranged from 3.33 to 5.67 . Total soluble solid and inulin content increased with the increase in chicory in the ratios, but $\mathrm{pH}$ increased with the increase in coffee in the ratios.

Color values ranged between 31.50 and 33.27 for $\mathrm{L}^{*}$, 0.15 and 0.89 for $a^{*}$ and -2.54 and -1.48 for $b^{*}$. $L^{*}$ value indicated the brightness, whereas $a^{*}$ value and $b^{*}$ value indicated red range and blue range, respectively. The increase in chicory in the ratios resulted in the increase in $\mathrm{L}^{*}$ values, whereas the increase in coffee in the ratios resulted in the increase in $a^{*}$ values and $b^{*}$ values.

Sensory parameters evaluated by 15 trained panelists are presented in Table 3. Significant differences $(\mathrm{P} \leq 0.05)$ among chicory-coffee ratios were observed for all parameters including color intensity, coffee aroma, sweetness, bitterness, and overall liking. The increase in chicory in the ratios caused significant reductions in color intensity, coffee aroma, and overall liking, but it greatly increased bitterness. The reduction in coffee aroma and the increase in bitterness as affected by the increase in chicory in the ratios were the most important factors reducing overall liking. It is interesting to note here that the ratio of $2: 3$ had overall liking of 137.40 , which was not significantly different from 148.00 of coffee alone, and it was the highest ratio for chicory to add into coffee without significant reduction in overall liking.

\subsection{Coffee-chicory mixture, coffee creamer and white sugar ratios}

The chicory-coffee ratio of 2:3 was selected for RDHCC product development by mixing coffee-chicory mixture with creamer and refined sugar. Then, nine formulae (recipes) were evaluated. The total soluble solids of nine formulae were statistically significant $(\mathrm{P} \leq 0.05)$, showing significant correlation between the ingredients and total soluble solid. The data were used to create the quadratic regression model for explaining the relationship of the quality values with the ingredients including chicory-coffee mixture $\left(\mathrm{X}_{1}\right)$, coffee creamer $\left(\mathrm{X}_{2}\right)$, and sugar $\left(\mathrm{X}_{3}\right)$ (Table 4$)$.

The effects of chicory-coffee mixture, coffee creamer and refined sugar on total soluble solids, $\mathrm{pH}$ and color values of RDHCC products from the contour plots surface are shown in Figure 1. Increase in creamer and refined sugar tended to increase total soluble solid in RDHCC products (Figure 1a), whereas increase in chicory-coffee mixture reduced $\mathrm{pH}$ values, which ranged from 5.5 to 6.2 (Figure $1 \mathrm{~b}$ ).

Table 2: Effects of the ratios of chicory-coffee mixture on total soluble solid, inulin, $\mathrm{pH}$ and color of chicory and coffee extract.

\begin{tabular}{|c|c|c|c|c|c|c|}
\hline \multirow{2}{*}{ Ratio } & \multirow{2}{*}{ Total soluble solid ( ${ }^{\circ}$ Brix) } & \multirow{2}{*}{ Inulin (g.100 $\mathrm{g}^{-1}$ dry weight) } & \multirow{2}{*}{$\mathrm{pH}$} & \multicolumn{3}{|c|}{ Color } \\
\hline & & & & $\mathrm{L}^{*}$ & $a^{*}$ & $\mathrm{~b}^{*}$ \\
\hline $0: 5$ & $3.40 \pm 0.10^{\mathrm{f}}$ & $0.01 \pm 0.00^{\mathrm{f}}$ & $5.67 \pm 0.02^{\mathrm{a}}$ & $31.50 \pm 0.04^{\mathrm{e}}$ & $0.89 \pm 0.04^{\mathrm{a}}$ & $-1.48 \pm 0.09^{\mathrm{a}}$ \\
\hline $1: 4$ & $5.57 \pm 0.06^{\mathrm{e}}$ & $1.77 \pm 0.06^{\mathrm{e}}$ & $4.84 \pm 0.02^{\mathrm{b}}$ & $31.94 \pm 0.05^{\mathrm{d}}$ & $0.78 \pm 0.03^{\mathrm{b}}$ & $-1.96 \pm 0.03^{b}$ \\
\hline $2: 3$ & $7.87 \pm 0.15^{\mathrm{d}}$ & $3.75 \pm 0.06^{\mathrm{d}}$ & $4.56 \pm 0.04^{\mathrm{c}}$ & $31.98 \pm 0.01^{\mathrm{d}}$ & $0.64 \pm 0.02^{\mathrm{c}}$ & $-2.17 \pm 0.03^{c}$ \\
\hline $3: 2$ & $8.93 \pm 0.06^{\mathrm{c}}$ & $5.50 \pm 0.18^{\mathrm{c}}$ & $3.94 \pm 0.03^{\mathrm{d}}$ & $32.46 \pm 0.02^{\mathrm{c}}$ & $0.33 \pm 0.05^{\mathrm{d}}$ & $-2.27 \pm 0.09^{c}$ \\
\hline $4: 1$ & $11.37 \pm 0.15^{\mathrm{b}}$ & $7.33 \pm 0.59^{\mathrm{b}}$ & $3.66 \pm 0.01^{\mathrm{e}}$ & $32.96 \pm 0.02^{\mathrm{b}}$ & $0.24 \pm 0.02^{\mathrm{e}}$ & $-2.43 \pm 0.05^{\mathrm{d}}$ \\
\hline $5: 0$ & $13.57 \pm 0.15^{\mathrm{a}}$ & $9.59 \pm 0.18^{\mathrm{a}}$ & $3.33 \pm 0.03^{\mathrm{f}}$ & $33.27 \pm 0.07^{\mathrm{a}}$ & $0.15 \pm 0.03^{\mathrm{f}}$ & $-2.54 \pm 0.03^{\mathrm{d}}$ \\
\hline
\end{tabular}

Mean \pm SD with different superscripts in each column indicate significant differences $(P \leq 0.05)$.

Table 3: Effects of the ratios of chicory-coffee mixture on color intensity, coffee aroma, sweetness, bitterness, and overall liking of coffee $(n=15)$.

\begin{tabular}{cccccc}
\hline Ratio & Color intensity & Coffee aroma & Sweetness & Bitterness & Overall liking \\
\hline $0: 5$ & $131.93 \pm 12.15^{\mathrm{a}}$ & $148.80 \pm 2.04^{\mathrm{a}}$ & $2.20 \pm 2.27^{\mathrm{e}}$ & $8.13 \pm 2.42^{\mathrm{f}}$ & $148.00 \pm 4.55^{\mathrm{a}}$ \\
$1: 4$ & $122.80 \pm 11.45^{\mathrm{ab}}$ & $134.73 \pm 12.40^{\mathrm{b}}$ & $6.53 \pm 3.40^{\mathrm{e}}$ & $26.80 \pm 9.13^{\mathrm{e}}$ & $141.13 \pm 6.28^{\mathrm{a}}$ \\
$2: 3$ & $116.80 \pm 12.85^{\mathrm{bc}}$ & $130.73 \pm 10.15^{\mathrm{b}}$ & $11.53 \pm 3.83^{\mathrm{d}}$ & $50.13 \pm 14.29^{\mathrm{d}}$ & $137.40 \pm 8.00^{\mathrm{a}}$ \\
$3: 2$ & $113.07 \pm 13.08^{\mathrm{bc}}$ & $104.73 \pm 10.89^{\mathrm{c}}$ & $17.47 \pm 6.52^{\mathrm{c}}$ & $99.53 \pm 15.78^{\mathrm{c}}$ & $90.13 \pm 25.88^{\mathrm{b}}$ \\
$4: 1$ & $106.27 \pm 17.24^{\mathrm{cd}}$ & $82.20 \pm 18.99^{\mathrm{d}}$ & $21.93 \pm 9.41^{\mathrm{b}}$ & $126.47 \pm 13.35^{\mathrm{b}}$ & $53.87 \pm 15.08^{\mathrm{c}}$ \\
$5: 0$ & $100.87 \pm 16.60^{\mathrm{d}}$ & $50.20 \pm 17.47^{\mathrm{e}}$ & $27.53 \pm 7.51^{\mathrm{a}}$ & $143.47 \pm 8.74^{\mathrm{a}}$ & $11.87 \pm 15.99^{\mathrm{d}}$ \\
\hline
\end{tabular}

Mean \pm SD with different superscripts in each column indicate significant differences $(P \leq 0.05)$. 
Table 4: Regression models of total soluble solid, $\mathrm{pH} \mathrm{L}^{*}, \mathrm{a}^{*}$ and $\mathrm{b}^{*}$ in mixture design experiment.

\begin{tabular}{crcc}
\hline Parameter & Regression equation & $\mathrm{R}^{2}$ & Significance level $(\mathrm{p} \leq 0.05)$ \\
\hline Total soluble solid & $-1205 \mathrm{X}_{1}+314 \mathrm{X}_{2}+151 \mathrm{X}_{3}+1466 \mathrm{X}_{1} \mathrm{X}_{2}+1325 \mathrm{X}_{1} \mathrm{X}_{3}-949 \mathrm{X}_{2} \mathrm{X}_{3}$ & 91.14 & 0.049 \\
$\mathrm{pH}$ & $3 \mathrm{X}_{1}+4.6 \mathrm{X}_{2}+3.56 \mathrm{X}_{3}-6 \mathrm{X}_{1} \mathrm{X}_{2}+7 \mathrm{X}_{1} \mathrm{X}_{3}+10.7 \mathrm{X}_{2} \mathrm{X}_{3}$ & 84.40 & 0.870 \\
$\mathrm{~L}^{*}$ & $-455 \mathrm{X}_{1}+352 \mathrm{X}_{2}+106.8 \mathrm{X}_{3}+180 \mathrm{X}_{1} \mathrm{X}_{2}+528 \mathrm{X}_{1} \mathrm{X}_{3}-586 \mathrm{X}_{2} \mathrm{X}_{3}$ & 98.95 & 0.125 \\
$\mathrm{a}^{*}$ & $27 \mathrm{X}_{1}-18.9 \mathrm{X}_{2}-1.0 \mathrm{X}_{3}+33 \mathrm{X}_{1} \mathrm{X}_{2}-19 \mathrm{X}_{1} \mathrm{X}_{3}+56 \mathrm{X}_{2} \mathrm{X}_{3}$ & 86.57 & 0.442 \\
$\mathrm{~b}^{*}$ & $1159 \mathrm{X}_{1}-107 \mathrm{X}_{2}-29.9 \mathrm{X}_{3}-1448 \mathrm{X}_{1} \mathrm{X}_{2}-1475 \mathrm{X}_{1} \mathrm{X}_{3}-436 \mathrm{X}_{2} \mathrm{X}_{3}$ & 79.71 & 0.541 \\
\hline
\end{tabular}

$\mathrm{X}_{1}=$ chicory-coffee mixture; $\mathrm{X}_{2}=$ coffee creamer; $\mathrm{X}_{3}=$ sugar.
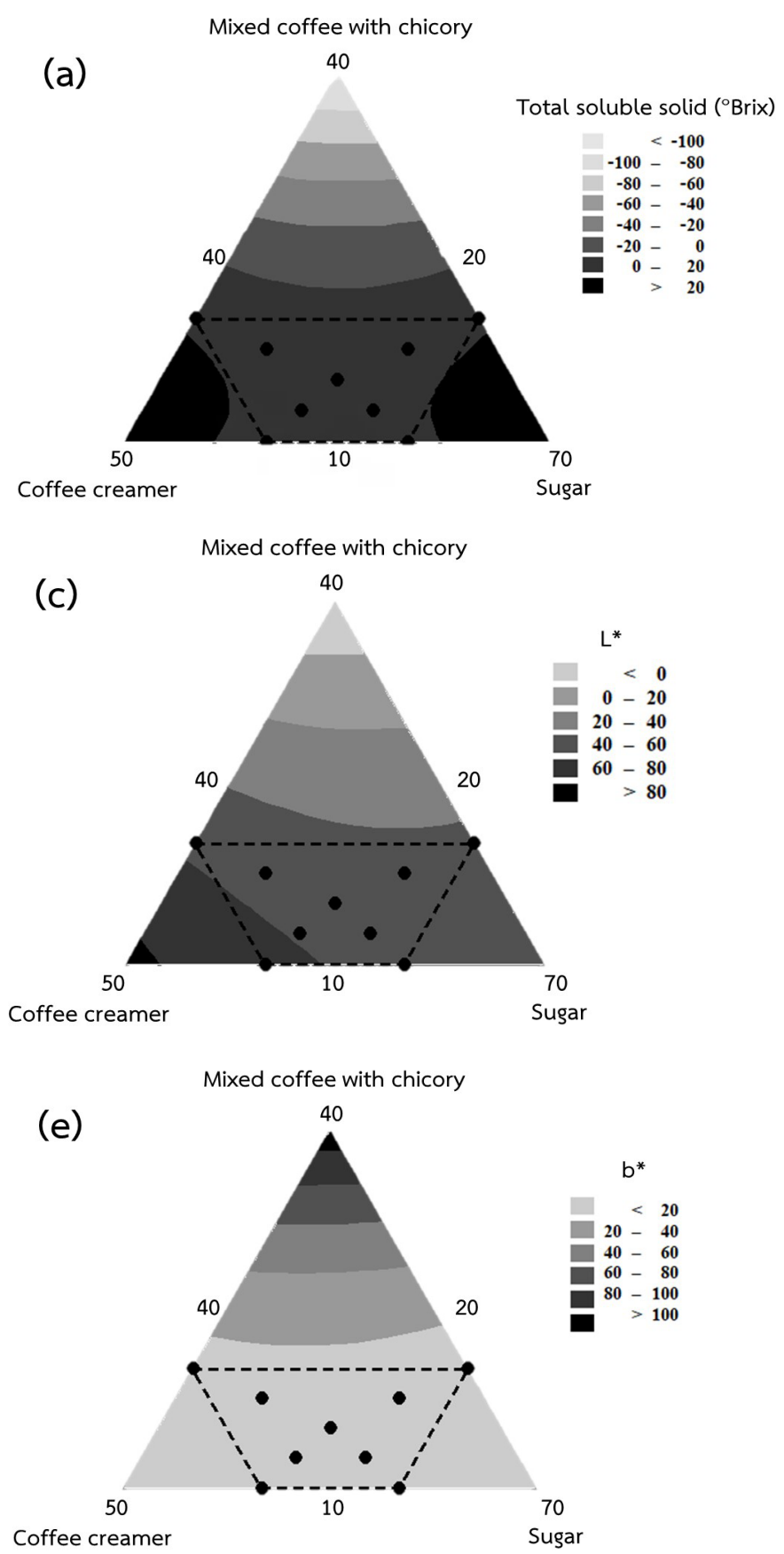
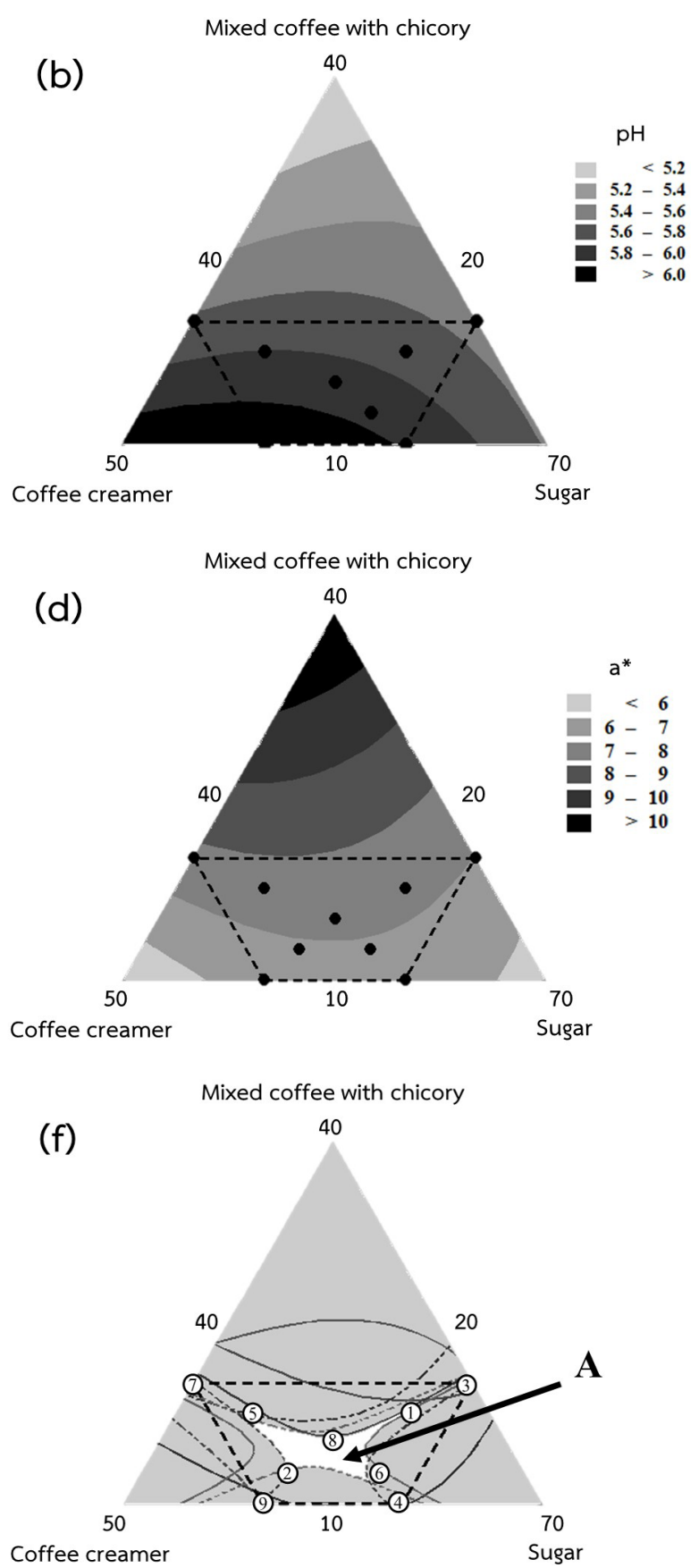

Figure 1: Mixture response surface contour plots displaying combined effects of mixed coffee with chicory, coffee creamer and sugar on total soluble solid (a), $\mathrm{pH}(\mathrm{b}), \mathrm{L}^{*}(\mathrm{c}), \mathrm{a}^{*}(\mathrm{~d}), \mathrm{b}^{*}(\mathrm{e})$, and contour plot for optimum overlapping [A] of coffee formulations (f). 
The resulted of analysis of CIE system color values are presented in Figure 1c -1e. The brightness $\left(\mathrm{L}^{*}\right)$ of RDHCC products greatly reduced with the increase in creamer (Figure 1c). The $\mathrm{a}^{*}$ was likely to be in the red range (Figure 1d), and $b^{*}$ was in the yellow range (Figure 1e). The $a^{*}$ and $b^{*}$ of RDHCC products tended to increase with chicory-coffee mixture.

The regression equation for total soluble solids, $\mathrm{pH}$, and color values from Table 4 were used to create a contour plot as shown in Figure 1a-1e. The graph was overlapped to find the appropriate area (Figure 1f). The total soluble solids (14-16 ${ }^{\circ}$ Brix), $\mathrm{pH}$ (5.5-6.5), L* (45-65), a* (6.5-7.5) and b* (10.5-11.5) were the criteria for selection of the appropriate formula.

The results of sensory evaluation of nine formulae are presented in Table 5. Formulae were significantly different ( $\mathrm{P}$ $\leq 0.05$ ) for all parameters including appearance, color, coffee aroma, taste, and overall liking. The ranges of all parameters were rather narrow, being from 6.45 to 8.05 for appearance, 6.20 to 7.95 for color, 5.70 to 8.10 for coffee aroma, 6.25 to 8.10 for taste, and 6.05 to 8.15 for overall liking. Formula 8 (chicory-coffee mixture $15.0 \%$, coffee creamer $32.5 \%$ and refined sugar $52.5 \%$ ) had the highest values for all parameters, and it was promising for further development of the products.

\subsection{Creamer substitutes}

Jerusalem artichoke powder, soybean milk powder, germinated riceberry powder, and golden banana powder were studied for coffee substitutes (Table 6). Creamer substitutes (including coffee creamer as a control) were significantly different $(\mathrm{P} \leq 0.05)$ for total soluble solid, $\mathrm{pH}$, color parameters $\left(\mathrm{L}^{*}, \mathrm{a}^{*}\right.$, and $\left.\mathrm{b}^{*}\right)$, appearance, color, coffee aroma, taste, and overall liking. The control formula (coffee creamer) had the highest total soluble solid (15.20 \pm 0.10$)$. High total soluble solid in this formula would be due to high glucose in the creamer (data not shown). The formula with coffee creamer also had the highest $\mathrm{pH}$ value, whereas the formula with golden banana powder had the lowest $\mathrm{pH}$ value. In general, formula with coffee creamer had the highest values of all color parameters $\left(\mathrm{L}^{*}, \mathrm{a}^{*}\right.$, and $\left.\mathrm{b}^{*}\right)$.

Table 5: Means for appearance, color, coffee aroma, taste, and overall liking of nine formulae of RDHCC products developed by mixing chicory-coffee mixture with different proportions coffee creamer substitutes $(n=20)$.

\begin{tabular}{|c|c|c|c|c|c|}
\hline Formulae & Appearance & Color & Coffee aroma & Taste & Overall liking \\
\hline 1 & $7.95 \pm 0.94^{\mathrm{a}}$ & $7.90 \pm 0.72^{\mathrm{a}}$ & $7.85 \pm 0.93^{\mathrm{a}}$ & $7.75 \pm 0.85^{\mathrm{ab}}$ & $7.60 \pm 1.23^{\mathrm{ab}}$ \\
\hline 2 & $7.70 \pm 1.08^{\mathrm{a}}$ & $7.50 \pm 1.05^{\mathrm{a}}$ & $7.55 \pm 1.12^{\mathrm{ab}}$ & $7.45 \pm 1.10^{\mathrm{abc}}$ & $7.45 \pm 1.23^{\mathrm{ab}}$ \\
\hline 3 & $6.85 \pm 1.14^{\mathrm{bc}}$ & $6.60 \pm 1.14^{\mathrm{b}}$ & $6.80 \pm 1.40^{\mathrm{c}}$ & $6.70 \pm 1.42^{\mathrm{cd}}$ & $6.45 \pm 1.47^{\mathrm{cd}}$ \\
\hline 4 & $6.45 \pm 1.36^{\mathrm{c}}$ & $6.20 \pm 1.28^{\mathrm{b}}$ & $5.70 \pm 1.42^{\mathrm{d}}$ & $6.25 \pm 1.48^{\mathrm{d}}$ & $6.05 \pm 1.54^{\mathrm{d}}$ \\
\hline 5 & $7.35 \pm 1.31^{\mathrm{ab}}$ & $7.60 \pm 1.14^{\mathrm{a}}$ & $7.70 \pm 1.13^{\mathrm{ab}}$ & $7.05 \pm 1.32^{\mathrm{bc}}$ & $7.10 \pm 1.48^{\mathrm{bc}}$ \\
\hline 6 & $7.65 \pm 0.88^{\mathrm{a}}$ & $7.50 \pm 0.51^{\mathrm{a}}$ & $7.65 \pm 0.88^{\mathrm{ab}}$ & $7.70 \pm 0.86^{\mathrm{ab}}$ & $7.50 \pm 1.15^{\mathrm{ab}}$ \\
\hline 7 & $7.80 \pm 0.95^{\mathrm{a}}$ & $7.70 \pm 0.66^{\mathrm{a}}$ & $7.75 \pm 1.12^{\mathrm{ab}}$ & $7.10 \pm 1.07^{\mathrm{bc}}$ & $7.00 \pm 1.03^{\mathrm{bc}}$ \\
\hline 8 & $8.05 \pm 1.00^{\mathrm{a}}$ & $7.95 \pm 0.76^{\mathrm{a}}$ & $8.00 \pm 0.97^{\mathrm{a}}$ & $8.10 \pm 0.79^{\mathrm{a}}$ & $8.15 \pm 1.09^{\mathrm{a}}$ \\
\hline 9 & $7.65 \pm 0.93^{\mathrm{a}}$ & $7.50 \pm 0.51^{\mathrm{a}}$ & $6.95 \pm 1.36^{\mathrm{bc}}$ & $7.00 \pm 1.38^{\mathrm{bcd}}$ & $6.85 \pm 1.57^{\mathrm{bcd}}$ \\
\hline
\end{tabular}

Mean $\pm S D$ with different superscripts in each column indicate significant differences $(P \leq 0.05)$.

Table 6: Effects of creamer substitutes on total soluble solid, color values ( $\mathrm{L}^{*}, \mathrm{a}^{*}$, and $\left.\mathrm{b}^{\star}\right)$, appearance, color, taste, coffee aroma, and overall liking of RDHCC products.

\begin{tabular}{|c|c|c|c|c|c|}
\hline Parameter & Coffee creamer & Jerusalem artichoke & Soymilk & Riceberry & Golden banana \\
\hline Total soluble solid ( ${ }^{\circ}$ Brix) & $15.20 \pm 0.10^{\mathrm{a}}$ & $14.23 \pm 0.02^{\mathrm{b}}$ & $13.82 \pm 0.02^{\mathrm{c}}$ & $11.67 \pm 0.03^{\mathrm{d}}$ & $11.40 \pm 0.04^{\mathrm{e}}$ \\
\hline $\mathrm{pH}$ & $6.01 \pm 0.02^{\mathrm{a}}$ & $5.13 \pm 0.02^{\mathrm{c}}$ & $5.26 \pm 0.03^{\mathrm{b}}$ & $4.78 \pm 0.01^{\mathrm{d}}$ & $4.07 \pm 0.01^{\mathrm{e}}$ \\
\hline $\mathrm{L}^{*}$ & $52.16 \pm 0.03^{\mathrm{a}}$ & $32.97 \pm 0.03^{\mathrm{e}}$ & $39.48 \pm 0.10^{\mathrm{b}}$ & $33.90 \pm 0.09^{\mathrm{d}}$ & $35.39 \pm 0.07^{\mathrm{c}}$ \\
\hline$a^{*}$ & $7.08 \pm 0.06^{\mathrm{a}}$ & $1.97 \pm 0.01^{\mathrm{e}}$ & $6.03 \pm 0.02^{\mathrm{b}}$ & $2.57 \pm 0.03^{\mathrm{d}}$ & $3.20 \pm 0.08^{c}$ \\
\hline$b^{*}$ & $11.83 \pm 0.03^{\mathrm{a}}$ & $-1.61 \pm 0.07^{\mathrm{d}}$ & $4.69 \pm 0.08^{\mathrm{b}}$ & $-1.51 \pm 0.11^{\mathrm{d}}$ & $0.10 \pm 0.02^{\mathrm{c}}$ \\
\hline Appearance & $8.05 \pm 1.00^{\mathrm{a}}$ & $7.00 \pm 1.30^{\mathrm{b}}$ & $7.85 \pm 0.75^{\mathrm{a}}$ & $6.65 \pm 1.31^{\mathrm{b}}$ & $6.45 \pm 1.39^{\mathrm{b}}$ \\
\hline Color & $7.95 \pm 0.76^{\mathrm{a}}$ & $6.90 \pm 1.33^{\mathrm{bc}}$ & $7.50 \pm 0.95^{\mathrm{ab}}$ & $6.55 \pm 1.47^{\mathrm{c}}$ & $6.03 \pm 1.45^{\mathrm{c}}$ \\
\hline Coffee aroma & $8.00 \pm 0.97^{\mathrm{a}}$ & $6.90 \pm 1.17^{\mathrm{bc}}$ & $7.60 \pm 0.68^{\mathrm{ab}}$ & $6.75 \pm 1.21^{\mathrm{c}}$ & $5.20 \pm 1.44^{\mathrm{d}}$ \\
\hline Taste & $8.10 \pm 0.79^{\mathrm{a}}$ & $6.45 \pm 1.23^{\mathrm{b}}$ & $7.45 \pm 0.60^{\mathrm{a}}$ & $5.90 \pm 1.41^{\mathrm{b}}$ & $4.95 \pm 1.39^{c}$ \\
\hline Overall liking & $8.15 \pm 1.09^{\mathrm{a}}$ & $6.35 \pm 1.27^{\mathrm{b}}$ & $7.45 \pm 0.94^{\mathrm{a}}$ & $5.75 \pm 1.45^{\mathrm{b}}$ & $4.80 \pm 1.28^{\mathrm{c}}$ \\
\hline
\end{tabular}

Mean $\pm S D$ with different superscripts in each row indicate significant differences $(P \leq 0.05)$. 
The formula with creamer had the highest values of all sensory parameters including appearance $(8.05 \pm 1.00)$, color (7.95 \pm 0.76$)$, coffee aroma $(8.00 \pm 0.97)$, taste $(8.10 \pm 0.79)$ and overall liking $(8.15 \pm 1.09)$. However, the formula with soymilk had average scores of appearance $(7.85 \pm 0.75)$, color $(7.50 \pm 0.95)$, coffee aroma $(7.60 \pm 0.68)$, taste $(7.45 \pm 0.60)$ and overall liking $(7.45 \pm 0.94)$, which were not statistically different from those of the formula with coffee creamer. Based on quality parameter and sensory parameters, the formula with soymilk was selected to produce RDHCC products in the next step.

\subsection{White sugar substitutes}

Stevia and erythritol were used as sweetener substitutes for refined sugar. All sweeteners (including refined sugar as a control) were not significantly different for most sensory parameters including appearance, color, coffee aroma, and taste except for overall liking (Table 7). Stevia was not significantly different from refined sugar control, but they were significantly higher $(\mathrm{P} \leq 0.05)$ than erythritol for overall liking. Therefore, stevia was a promising sweetener for further development of the products.

\subsection{Herbal supplements}

Significant differences $(\mathrm{P} \leq 0.05)$ among herb supplements (including no herb control) were found for appearance, color, coffee aroma, taste, and overall liking (Table 8). The formular with cordyceps was not significantly different from no-herb control for all parameters, whereas ginger, lemongrass, and fingerroot were significantly different from no-herb control for at least two parameters especially for fingerroot, which was significantly different from no-herb control for all parameters.

\section{DISCUSSION}

\subsection{Coffee and chicory ratios}

Generally, chicory root contains $68 \%$ inulin, $14 \%$ sucrose, $5 \%$ cellulose, $6 \%$ protein, $4 \%$ ash, and $3 \%$ other components, respectively. Moreover, there are high polysaccharides in fructan group including oligofructose and inulin (Nwafor; Shale; Achilonu, 2017). The molecular structure of inulin is heteropolymer polysaccharide. There is more than 1 type of sugar molecules connecting in the inulin molecules. Inulin contains 10-60 molecules of fructose sugar in the chain, but the molecules at the starting and closing ends are glucose molecules. The molecular structure of inulin is the same as oligofructose, which is an oligosaccharide. Inulin is a polymer with longer chain than oligofructose. Therefore, it does not have a sweet taste and is only slightly soluble. Oligofructose consists of less than 10 single molecules of sugar. It results in a slightly sweet taste, approximately 30-50\% compared to sucrose and dissolves well in water (Kelly, 2008). Obviously, the main chemical composition of chicory roots is carbohydrate. The total soluble solid of the mixture tended to increase with the increase in chicory in the mixture.

There are many kinds of phenolic compounds in chicory root such as protocatechuic acid, chlorogenic acid, caffeic acid, m-coumaric acid, and p-coumaric acid (Damondaran; Parkin, 2017). The increase in chicory in the ratios resulted in the increase in acidity of the mixture extract.

Table 7: Means for appearance, color, coffee aroma, taste, and overall liking of RDHCC products as affected by sweetener substitutes $(n=20)$.

\begin{tabular}{cccccc}
\hline Sweetener & Appearance & Color & Coffee aroma & Taste & Overall liking \\
\hline Sugar & $7.85 \pm 075^{\text {ns }}$ & $7.50 \pm 0.95^{\text {ns }}$ & $7.60 \pm 0.68^{\text {ns }}$ & $7.45 \pm 0.60^{\text {ns }}$ & $7.45 \pm 0.94^{\mathrm{a}}$ \\
Stevia & $7.55 \pm 0.83^{\text {ns }}$ & $7.40 \pm 0.94^{\text {ns }}$ & $7.55 \pm 0.83^{\text {ns }}$ & $7.20 \pm 0.95^{\text {ns }}$ & $7.30 \pm 1.00^{\text {a }}$ \\
Erythritol & $7.40 \pm 1.10^{\text {ns }}$ & $7.25 \pm 1.02^{\text {ns }}$ & $7.40 \pm 0.94^{\text {ns }}$ & $6.90 \pm 1.12^{\text {ns }}$ & $6.50 \pm 1.10^{\text {b }}$ \\
\hline
\end{tabular}

Mean $\pm S D$ with different superscripts in each column indicate significant differences $(P \leq 0.05)$.

Table 8: Means for appearance, color, coffee aroma, taste, and overall liking of RDHCC products as affected by herbs $(\mathrm{n}=20$ ).

\begin{tabular}{cccccc}
\hline Herb & Appearance & Color & Coffee aroma & Taste & Overall liking \\
\hline Control & $7.55 \pm 0.83^{\mathrm{a}}$ & $7.40 \pm 0.94^{\mathrm{a}}$ & $7.55 \pm 0.83^{\mathrm{a}}$ & $7.20 \pm 0.95^{\mathrm{a}}$ & $7.30 \pm 1.00^{\mathrm{a}}$ \\
Cordyceps & $7.40 \pm 0.75^{\mathrm{ab}}$ & $7.20 \pm 0.89^{\mathrm{ab}}$ & $7.35 \pm 0.81^{\mathrm{a}}$ & $7.10 \pm 0.91^{\mathrm{a}}$ & $7.15 \pm 1.04^{\mathrm{a}}$ \\
Ginger & $7.05 \pm 1.15^{\mathrm{ab}}$ & $6.90 \pm 1.17^{\mathrm{ab}}$ & $6.15 \pm 1.53^{\mathrm{ab}}$ & $5.95 \pm 1.36^{\mathrm{b}}$ & $5.95 \pm 1.47^{\mathrm{b}}$ \\
Lemongrass & $6.95 \pm 1.10^{\mathrm{ab}}$ & $6.95 \pm 1.05^{\mathrm{ab}}$ & $6.85 \pm 1.18^{\mathrm{b}}$ & $6.05 \pm 1.15^{\mathrm{b}}$ & $6.25 \pm 1.21^{\mathrm{b}}$ \\
Fingerroot & $6.70 \pm 1.25^{\mathrm{c}}$ & $6.55 \pm 1.15^{\mathrm{c}}$ & $4.60 \pm 1.70^{\mathrm{c}}$ & $4.85 \pm 1.73^{\mathrm{c}}$ & $4.70 \pm 1.78^{\mathrm{c}}$ \\
\hline
\end{tabular}

Mean $\pm S D$ with different superscripts in each column indicate significant differences $(P \leq 0.05)$. 
Normally, roasting is an important step affecting the taste and color of coffee and chicory. The coffee beans and chicory roots are roasted at $120-300^{\circ} \mathrm{C}$ resulting in a dark brown color (Indzere et al., 2018). The non-enzymatic browning reaction, Maillard reaction, occurs between reducing sugars and amino acids, proteins, or other nitrogen compounds, being heat acting during roasting as a catalyst (Baek; Cadwallader, 1998; Mojska; Gielecinska, 2013). Moreover, caramelization is caused by the breakdown of sugar when heated in an absence of water that causing volatile compounds or caramel flavorings and resulting in browning (Paravisini et al., 2017).

The chemical compositions of coffee and chicory affect the color, aroma, sweetness, and bitterness in which the panelists can sense. The color and aroma of roasted coffee are caused by volatile compounds, which are accounted for more than 800 types. There are many volatile substances in raw coffee beans that provide an unwanted odor feature, consisting of alkanes, alkenes, pyridines, quinolines, pyrroles, arylamides and polyamines. The various volatile compounds in coffee beans depend on many factors such as species, conditions of cultivation, and processing. The compounds will be changed and increased when the coffee beans are roasted. The volatile compounds directly related to coffee aroma are a heterocyclic compound that contains nitrogen, oxygen, and sulfur as the components. The non-volatile compounds, which are carbohydrates, proteins, trigonelline, free amino acids, fats, and various non-volatile acids, are precursors of the aroma in coffee. The formation of volatile compounds in coffee is involved in important reactions, including Maillard reaction and caramelization, which result in the browning reaction described above. Furthermore, pyrolysis is a reaction in which organic compounds decompose into smaller compounds under high temperature and without oxygen. The product from pyrolysis reaction is carbon dioxide gas. In practice, it is unlikely that there will be no oxygen in the roasting environment. Because some of the oxygen appears in each step of the reaction, oil leaks out, roasting process produces smell, and the coffee beans become dark brown, brittle, easily brittle, swollen. Furan compounds, which have larger influence on the coffee aroma than other compounds are found in roasted coffee beans. The compounds are caused by the pyrolysis reaction of sugar giving the caramel smell. The pyrazines group is the second most important group found to have the aroma of roasted coffee, roasted cereal and toast smell of bread. Pyrole substances give caramel and mushroom scents. In addition, the thiophene compound, which has a meat odor, is found due to the Maillard reaction (Buffo; CardelliFreire, 2004).

The panelists received a slightly sweet taste. The sweetness of chicory coffee extract increased with the increase in chicory in the ratios. The increase in sweetness would be due to high oligo fructose, inulin, and sucrose in chicory (Nwafor;
Shale; Achilonu, 2017). In terms of Mono- and disaccharides, the chicory roots contain high amounts of sucrose $\left(15.2 \mathrm{~g} .100 \mathrm{~g}^{-1}\right.$ dry matter), fructose $\left(9.53 \mathrm{~g} .100 \mathrm{~g}^{-1}\right.$ dry matter) and glucose (0.61 g.100 ${ }^{-1}$ dry matter) (Stokle; Kruse, 2019). It gives a sweet taste. Moreover, inulin is a polymer with a longer string than oligofructose. In comparison, oligofructose is smaller in molecular size than Inulin. It contains less than 10 single molecules of sugar that it has a slightly lower sweet taste, approximately 30-50\% compared to sucrose (Damondaran; Parkin, 2017). In general, coffee has caffeine, which has a slightly bitter taste (Paravisini et al., 2017).

Adding chicory in chicory-coffee mixture increased bitterness, and, therefore, it greatly reduced overall liking. Bitterness in chicory is caused by the presence of the sesquiterpene lactones group, such as lactucin, 8-deoxylactucin, lactucopicrin, and 11ß-dihydro-derivatives. These phytochemicals are responsible for their bitterness in chicory (Nwafor; Shale; Achilonu, 2017). The ratios of chicory-coffee mixture should not be greater than 2:3 because the ratios higher than these greatly affected overall liking.

The panelists commented that adding chicory into coffee at high ratios greatly reduced coffee aroma, and the mixtures were too bitter. Therefore, the ratio of $2: 3$ was acceptable, and it was selected for developing a RDHCC product in the next step. This ratio has higher inulin content than the ratios of 0:5 and 1:4, and the over liking scores were not significantly different. Perhaps, it is the choice for the consumers, who like to drink pure coffee without milk, coffee creamer and sweeteners.

\subsection{Coffee-chicory mixture, coffee creamer and white sugar ratios}

From chemical analysis, the coffee creamer used in this study contained up to $61 \%$ glucose syrup, $34 \%$ vegetable fat and $5 \%$ other components. Both glucose syrup in coffee creamer and sucrose in white sugar in the form of crystal directly affected the total soluble solids. The amount of sucrose in coffee beans was approximately $6-8.3 \%$ of dry weight (Caporaso et al., 2018). It was lower than sucrose in chicory, which had $14 \%$ of dry weight (Nwafor; Shale; Achilonu, 2017). However, the total soluble solids in chicorycoffee mixture are lower than those in coffee creamer and white sugar. Therefore, the amount of coffee creamer and white sugar played an important role in the change in the total soluble solid content of RDHCC products.

In general, coffee has a $\mathrm{pH}$ range between 4.5 and 7.0 (Rao; Fuller, 2018). Coffee bean consists of many organic acids, including chlorogenic acid, citric acid, malic acid, oxalic acid, tartaric acid, lactic acid, pyruvic acid, and acetic acid (Marek et al., 2020). Many organic acids such as protocatechuic acid, chlorogenic acid, caffeic acid, m-coumaric acid, p-coumaric acid, and others were found in chicory (Nwafor; Shale; 
Achilonu, 2017). These acids contribute to a decrease in the $\mathrm{pH}$ of the RDHCC products.

Change in the color of RDHCC products was the result of the browning reaction during the roasting process as described earlier. The amount of coffee creamer affected the brightness of RDHCC products. Generally, coffee creamer has a white color with glucose syrup and vegetable fat as the main components. When the coffee creamer was added in high amounts, it reduced the color intensity of chicory-coffee mixture, resulting in the increased brightness of RDHCC products.

The results indicated that the overlapping areas (the letter A) were suitable areas for the mixture of RDHCC products. The formula 8 containing $15.0 \%$ chicory-coffee mixture, $32.5 \%$ coffee creamer, and $52.5 \%$ sugar was in overlapping areas. Sensory parameters (Table 5) were also considered for selecting the most suitable formula, and formula 8 was the highest for all parameters. Based on quality values and sensory parameters, formula 8 was selected for further development of RDHCC products in the next step.

\subsection{Creamer substitutes}

Jerusalem artichoke is rich in soluble dietary fiber, and it is considered to be low calorie diet. It contains about $83.1 \%$ carbohydrates by dry weight, and most carbohydrates are in the forms of oligofructose and inulin as in chicory. The main component of sugar in Jerusalem artichoke is fructose and glucose (Bui et al, 2016). Normally, soymilk contains 33\% carbohydrate and $16.6 \%$ soluble sugar. The most common sugars are sucrose (41.3-67.5\%), raffinose (5.2-15.8\%) and stachyose (12.1-35.2\%) (Hou et al., 2009). Germinated riceberry powder (whole grain) had $73-77 \%$ carbohydrates and had a high amount of amylose (Settapramote et al., 2018). It had a moderate to low glycemic index (Suttireung et al., 2019). The golden banana powder is produced from unripe bananas, which have lower sweetness or sugar than ripe bananas. Bananas are a source of carbohydrates. Golden banana powder contains 58.9\% resistant starch and $44.7 \%$ amylose (Bookong; Bunmee; Ruenkeaw, 2014). Generally, bananas contain many kinds of organic acids such as malic acid, citric acid, oxalic acid, and phosphoric acid. These organic acids change according to the ripening stages of the bananas (Etienne et al., 2013). These acids may affect the decrease in $\mathrm{pH}$ value.

For the changes in color values, the formulae with the coffee creamer addition had the highest values of $\mathrm{L}^{*}$, $a^{*}$ and $b^{*}$ in the reddish-brown range, and other formulae were in the range of dark brown to black. The intense colors of various coffee formulas were the result of the different chemical compositions in the raw materials. The formulae with the addition of Jerusalem artichoke and golden banana may have an enzymatic browning reaction after coffee making resulting in dark brown to dark colors (Thaiphanit;
Anprung, 2013; Charoenphun; Puttha, 2020). Riceberry powder contains anthocyanins giving red, purple, and dark blue colors (Settapramote et al., 2018). If the $\mathrm{pH}$ values are lower than 3 , the anthocyanins give red color. For $\mathrm{pH}$ values about 7-8, anthocyanins will have a purple color. If the $\mathrm{pH}$ values are higher than 11, the anthocyanins will turn blue color (Damondaran; Parkin, 2017).

In previous study, soymilk powder contained 3.0\% protein, $1.5 \%$ fat, $1.5 \%$ carbohydrates. It is a source of many essential amino acids such as leucine, isoleucine, lysine, and methionine (Sugkhaphan; Kijroongrojana, 2009). Soymilk contained carotenoids with yellow, red, and orange colors (Monma et al., 1994). Incorporation of soymilk powder into the products may lead to a higher brightness value than incorporation of Jerusalem artichoke, riceberry, and golden banana into the products.

\subsection{White sugar substitutes}

Other sweeteners with low calories were studies for refined sugar substitutes. The average score for overall liking of stevia extract was not significantly different from that of refined sugar, but it was significantly higher than that of erythritol. Stevia extract and erythritol are commonly used as sugar substitutes in beverage products. They are sweet but provide low or zero calories.

The total soluble solids of sugar, stevia extract, and erythritol formulas were 13.8 2.1 and $4.1^{\circ}$ Brix, respectively. Stevia extract is 200-300 times sweeter than sugar, but it does not provide energy value. It has the most sugar-like flavor, and the sweetness stays in the mouth for a long time. Erythritol is a sugar alcohol with sweetness of $60-70 \%$ compared to sugar, and provides $0.2 \mathrm{kcal}$ per $\mathrm{g}$. It has a taste like sucrose but with a slightly sour and slightly bitter (Gandhi et al., 2018). Therefore, stevia extract was suitable as a sweetener substitute for sugar in RDHCC products in the next step.

\subsection{Herbal supplements}

The last step for development of RDHCC products was to find the most suitable herb for the products. The trained panelists were invited to evaluate four herbs consisting of cordyceps, ginger, lemongrass, and fingerroot.

Cordyceps (Cordyceps militaris) is an insect mold in the Ascomycetes group. It has medicinal effects consisting of many important substances including monosaccharides, disaccharides, polysaccharides (beta-glucan), cordycepin, cordycepic acid, adenosine, amino acids, vitamins and many minerals. There are important properties, and it has been used in traditional Chinese medicine. Beta-glucan, an antioxidant, increases immunity and reduces blood sugar levels. Cordycepin has kidney care and antibacterial properties and increases the efficiency of blood circulation. It helps increase the body's metabolism and prevents bleeding in the brain, 
that causes blood clots, ischemic heart disease, and asthma (Xu et al., 2019).

Ginger, lemongrass, and fingerroot are common herbs and used as spices in Thai culinary, and they are also used in Thai traditional medicine. In this study, only cordyceps was compatible to no-herb control for all parameters, whereas fingerroot was poorest for all parameters. The panelists did not like fingerroot because of its strong pungency. Cordyceps was selected for the final product.

\section{CONCLUSIONS}

The objective of this research project was to develop the appropriate formula of RDHCC product. The study was carried out step by step. Firstly, the authors evaluated the ratios of chicory-coffee mixture to select the most appropriate one. Secondly, the authors used the selected ratio to evaluate the suitable ratios of creamer and refined sugar in the product. Thirdly, the authors evaluated the appropriate ingredients to replace creamer and refined sugar. Finally, the authors evaluated the appropriate herb for the product.

The prototype formula of RDHCC product contained coffee, chicory, soymilk powder, stevia extract, and cordyceps at the proportions of $4.5,3,16.3,0.5$ and $0.1 \%$, respectively. The RDHCC products may be produced as an alternative food for consumers, who have dietary restrictions and want to avoid high fat and sugar content, and those who like to eat herbs. The knowledge gained from this research can be used as a guideline for developing RDHCC products, which can be further expanded into commercial production. The research is useful for the readers and coffee industry to develop similar products.

However, the product might be used in limited market segment especially for the consumers with common culture of the sampling group. Care must be taken to extrapolate the results to different cultural groups because consumer behaviors might be different in different cultural groups. Further studies may be conducted regarding proper packaging and shelf life of products. More local herbs that have medicinal properties and go along well with coffee should be explored.

\section{ACKNOWLEDGEMENTS}

The authors would like to acknowledge the Faculty of Agricultural Technology and the Faculty of Science and Social Sciences, Burapha University, Sakaeo Campus, Sakaeo, Thailand for providing the experimental field and scientific instruments. The North Central Regional Plant Introduction Station (NCRPIS), USA is acknowledged for donation of chicory germplasm.

\section{REFERENCES}

BAEK, H. H.; CADWALLADER, K. R. Roasted chicory aroma evaluation by gas chromatography/mass spectrometry/olfactometry. Journal of Food Science, 63(2):234-237, 1998.

BOOKONG, J.; BUNMEE, T.; RUENKEAW, P. Application of resistant starchfrom unripe banana "Hom Thong" (Musasapientum L., AAA group) in pasta. Journal of Food Technology, Siam University, 10(1):19-29, 2014.

BUFFO, R. A.; CARDELLI-FREIRE, C. Coffee flavour: An overview. Flavour and Fragrance Journal, 19:99-104, 2004.

BUI, C. V. et al. Conversion of Jerusalem artichoke tuber powder into Fructooligosaccharides, fructose, and glucose by a combination of microwave heating and $\mathrm{HCl}$ as a catalyst. Thammasat International Journal of Science and Technology, 21(3):31-45, 2016.

CAPORASO, N. et al. Non-destructive analysis of sucrose, caffeine and trigonelline on single greencoffee beans by hyperspectral imaging. Food Research International, 106:193-203, 2018.

CHAROENPHUN, N.; PUTTHA, R. Effects of methods on delay browning of ready-to-eat fresh pre-cut Jerusalem artichokes. Thai Journal of Science and Technology, 28(3):468-481, 2020.

DAMONDARAN, S.; PARKIN, K. L. Fennema's Food Chemistry. Florida: CRC Press, Taylor \&. Francis Group, 2017. 1123p.

DO, Y. G. et al. Supplementation of non-dairy creamerenriched high-fat diet with D-allulose ameliorated blood glucose and body fat accumulation in $\mathrm{C} 57 \mathrm{BL} / 6 \mathrm{~J}$ mice. Applied Sciences, 9(2750):1-17, 2019.

DUNCAN, D. B. Multiple range and multiple F tests, Biometrics, 11:1-42, 1955.

ETIENNE, A. et al. A model approach revealed the relationship between banana pulp acidity and composition during growth and postharvest ripening. Scientia Horticulturae, 162:125-134, 2013.

GANDHI, S. et al. Natural sweeteners: Health benefits of stevia. Foods and Raw Materials, 6(2):392-402, 2018.

HOU, A. et al. Sugar variation in soybean seed assessed with a rapid extraction and quantification method. International Journal of Agronomy, 484571: 1-8, 2009. 
INDZERE, Z. et al. The benchmarking of chicory coffee's production. Energy Procedia, 147:631-635, 2018.

INTERNATIONAL COFFEE ORGANIZATION - ICO. Coffee market report. 2020. Available in: $<$ http://www. ico.org/\#: :text=World $\% 20$ coffee $\% 20$ production $\% 20$ is $\% 20$ estimated,estimated $\% 20$ surplus $\% 20$ of $\% 20$ 952\%2C000\%20bags $>$. Access in: December, 27, 2020.

KELLY, G. Inulin-type prebiotics - A review: Part 1. Alternative Medicine Review, 13(4): 315-329, 2008.

MAREK, G. et al. Detection and differentiation of volatile compound profiles in roasted coffee arabica beans from different countries using an electronic nose and GC-MS. Sensors, 20(2124):2-11, 2020.

MOJSKA, H.; GIELECINSKA, I. Studies of acrylamide level in coffee and coffee substitutes: Influence of raw material and manufacturing conditions. Roczniki Panstwowego Zakladu Higieny, 64(3):173-181, 2013.

MONMA, M. et al. Carotenoid components in soybean seeds varying with seed color and maturation stage. Bioscience, Biotechnology, and Biochemistry, 58(5):926-930, 1994.

MOON, K. B. et al. Expression of Jerusalem artichoke (Helianthus tuberosus L.) fructosyltransferases, and high fructan accumulation in potato tubers, KSABC The Korea Society for Applied Biological Chemistry, 62(74):1-9, 2019.

NWAFOR, I. C.; SHALE, K.; ACHILONU, M. C. Chemical composition and nutritive benefits of chicory (Cichorium intybus) as an ideal complementary and/or alternative livestock feed supplement. Scientific World Journal Article, 7343928:1-11, 2017.

PARAVISINI, L. et al. Caramel flavour perception: Impact of the non-volatile compounds on sensory properties and in-vitro aroma release. Food Research International, 100:209-215, 2017.

PUTTHA, R. et al. Genotypic variability and genotype by environment interactions for inulin content of
Jerusalem artichoke germplasm. Euphytica, 183:119$131,2012$.

RAO, N. Z.; FULLER, M. Acidity and antioxidant activity of cold brew cofee. Scientific Reports, 8:1-9, 2018.

SENGPIEL, V. et al. Maternal caffeine intake during pregnancy is associated with birth weight but not with gestational length: Results from a large prospective observational cohort study. BMC Medicine, 11(42):1-18, 2013.

SETTAPRAMOTE, N. et al. Physiochemical, antioxidant activities and anthocyanin of riceberry rice from different locations in Thailand. Food and Applied Bioscience Journal, 6:84-94, 2018.

STOKLE, K.; KRUSE, A. Extraction of sugars from forced chicory roots. Biomass Conversion and Biorefinery, 9:699-708, 2019.

STONE, H. Manual on descriptive analysis testing for sensory evaluation. ASTM International. p.15-21, 1992.

SUGKHAPHAN, P.; KIJROONGROJANA, K. Optimization of prebiotics in soybean milk using mixture experiments. Songklanakarin Journal of Science and Technology, 31(5):481-490, 2009.

SUTTIREUNG, P. et al. Riceberry rice puddings: Rice-based low glycemic dysphagia diets. Asia Pacific Journal of Clinical Nutrition, 28(3):467-475, 2019.

TANJOR, S. et al. Inulin and fructooligo sacharides in different varieties of Jerusalem artichoke (Helianthus tuberosus L.). KKU Research Journal, 17(1):25-34, 2012.

THAIPHANIT, S.; ANPRUNG, P. Inhibition of browning reaction in pasteurized fragrant banana puree. Journal of Food Technology, Siam University, 9(1):39-51, 2013.

$\mathrm{XU}$, L. et al. Optimization of polysaccharide production from Cordyceps militaris by solid-state fermentation on rice and its antioxidant activitie. Foods, 8(11):1-9, 2019. 